\title{
FORMAÇÃO DE PROFESSORES: A EXPERIÊNCIA DO PIBID - SUBPROJETO DE PEDAGOGIA DA FACULDADE DE FILOSOFIA, CIÊNCIAS E LETRAS DE ITUVERAVA
}

\author{
GRACIOLI, Maria Madalena ${ }^{1}$ \\ ANDRADE, Lucimary B. Pedrosa de ${ }^{1}$ \\ GIMENES, Priscila Alvarenga Cardoso ${ }^{1}$
}

\begin{abstract}
RESUMO: Várias pesquisas têm revelado a fragilidade da formação inicial dos professores tendo em vista que a maioria dos currículos dos cursos de licenciaturas está fundamentada em modelos nos quais os estudos teóricos estão desarticulados das práticas pedagógicas, impossibilitando aos licenciandos experiências formativas a partir das situações concretas do exercício do trabalho docente. Considerando a necessidade de se repensar os modelos atuais da formação superior de professores, foi criado pelo Ministério da Educação (MEC), por meio da Coordenação de Aperfeiçoamento de Pessoal de Nível Superior - CAPES, o Programa Institucional de Bolsas de Iniciação à docência - PIBID. Desde 2012 a Faculdade de Filosofia, Ciências e Letras de Ituverava - FFCL - participa do programa, desenvolvendo subprojetos com alunos das licenciaturas de Pedagogia, Letras, Matemática, Biologia e História. O presente artigo tem como objetivo apresentar aspectos da organização e do desenvolvimento das ações do subprojeto de Pedagogia aplicado nas séries iniciais do ensino fundamental das escolas públicas municipais de Ituverava, o qual enfoca o trabalho com jogos no contexto educacional. O estudo foi desenvolvido por meio de pesquisa bibliográfica e documental fundamentado em autores que discutem a formação docente e a importância dos jogos na educação e em documentos legais como a Lei de Diretrizes e Bases da Educação (1996), as Diretrizes para o curso de Pedagogia (2006) e os documentos relativos ao PIBID. Os resultados obtidos com a realização do subprojeto de Pedagogia evidenciam a relevância do programa enquanto política pública destinada à formação de professores e sua contribuição no aprimoramento das práticas pedagógicas desenvolvidas na educação básica.
\end{abstract}

Palavras-chave: Formação de professores. Jogos na educação. Pedagogia. PIBID.

SUMMARY: Several researches have revealed the fragility of the initial formation of teachers since most of the curricula of graduation courses is based on models in which the theoretical studies are disarticulated of the pedagogical practices, making it impossible for students a formative experience from real situations of teaching work. Considering the need to rethink the current models of teachers training, MEC (Ministério da Educação), through the support of Coordenação de Aperfeiçoamento de Pessoal de Nível Superior - CAPES-, created a program called Programa Institucional de Bolsas de Iniciação à docência (PIBID). Since 2012 Faculdade de Filosofia, Ciência Letras of Ituverava city - FFCL- participates in this program, developing subprojects with students in courses in Pedagogy, Letters, Mathematics, Biology and History. The aim of this paper is present aspects of the organization and development of the actions of the Pedagogy subproject developed in the initial grades of elementary school in municipal public schools of Ituverava city, which focuses on work with games in the educational context. The study was developed through bibliographical and documentary research based on authors who discuss teacher education and the importance of games in education and, legal documents such as Lei de Diretrizes e Base da Educação (1996), Diretrizes para o curso de Pedagogia (2006) and the documents related to PIBID. The results obtained with Pedagogy subproject show the relevance of the program as a public policy aimed at teacher training and its contribution in improving pedagogical practices developed in basic education.

Keywords: Teacher training. Games in educational context. Pedagogy. PIBID.

\section{INTRODUÇÃO}

A formação docente requer a articulação entre os conhecimentos teóricos e práticos, de forma que

\footnotetext{
${ }^{1}$ Faculdade de Filosofia Ciências e Letras de Ituverava
} 
os futuros professores possam adquirir, durante os cursos de licenciaturas, saberes teóricos, práticos, metodológicos e experiências para atuarem em sala de aula. Desta forma, é preciso que os licenciandos vivenciem experiências formativas da prática pedagógica por meio da aproximação com a realidade escolar, construindo conhecimentos necessários para a identidade docente.

Considerando a importância da articulação da relação teoria e prática e a necessidade de se repensar a formação docente para atender as demandas atuais da educação em nossa sociedade foi criado pelo Governo Federal o Programa Institucional de Bolsas de Iniciação à Docência - PIBID - gerenciado pela Coordenação de Aperfeiçoamento de Pessoal de Nível superior - CAPES. O PIBID tem como objetivo o aperfeiçoamento e a valorização da formação de professores, por meio da inserção de graduandos dos cursos de licenciatura nas escolas de educação básica, com o intuito de lhes possibilitar a articulação entre teoria e prática na atuação direta com os alunos, e oportunizar a vivência no cotidiano escolar. Desde 2012 a Faculdade de Filosofia, Ciências e Letras de Ituverava - FFCL, participa do PIBID desenvolvendo subprojetos com alunos das licenciaturas de Pedagogia, Letras, Biologia, Matemática ${ }^{2}$ e História.

O presente artigo tem como objetivo apresentar aspectos da organização e do desenvolvimento das ações do subprojeto de Pedagogia desenvolvido nas séries iniciais do ensino fundamental de escolas públicas municipais da cidade de Ituverava, o qual enfoca o trabalho com jogos no contexto educacional. Atualmente o subprojeto de Pedagogia conta com a participação de vinte e duas alunas bolsistas, duas professoras da faculdade que atuam como coordenadoras do subprojeto, e quatro professoras da educação básica que exercem a função de supervisoras.

Utilizamos para compor esse estudo pesquisa bibliográfica e documental, fundamentada em autores que discutem a formação docente e a importância dos jogos na educação, e em documentos legais como a Lei de Diretrizes e Bases da Educação (1996), as Diretrizes para o curso de Pedagogia (2006) e os documentos relativos ao PIBID. Os resultados obtidos com a realização do subprojeto de Pedagogia evidenciam a relevância do programa enquanto política pública destinada à formação inicial de professores e sua contribuição no aprimoramento das práticas pedagógicas desenvolvidas na educação básica.

\section{A FORMAÇÃO DE PROFESSORES E A IMPORTÂNCIA DA ARTICULAÇÃo ENTRE TEORIA E PRÁTICA}

No momento de transformação da sociedade industrial para a sociedade da informação e do conhecimento é preciso refletir sobre o papel da escola, do currículo, e das práticas docentes para a implementação de novas formas de ensinar e aprender.

A ênfase no processo educativo não consiste mais em como ensinar, mas em como o aluno aprende, reconhecendo o professor como um sujeito mediador e facilitador da aprendizagem, o que tem contribuído para o desenvolvimento de muitos estudos acerca da formação docente, visto ser esta uma demanda constante no contexto de mudanças de paradigmas sociais e educacionais.

Vasconcellos (2011) afirma que a formação inicial e continuada é uma exigência para qualquer profissão e que no exercício da docência ela se torna muito especial, considerando três razões: a complexidade da atividade docente, as crescentes demandas impostas à escola na sociedade atual e as fragilidades da formação inicial dos educadores. Em relação a esta terceira razão o autor afirma:

${ }^{2}$ O subprojeto de Matemática foi encerrado no final do ano de 2016, por não ter formado novas turmas no curso de licenciatura em Matemática.

Nucleus,v.14,n.2,out.2017 
Por fim, a terceira está representada pela frágil formação inicial dos educadores, tanto pela qualidade da formação frequentemente disponibilizada, quanto pela falta de interesse do acadêmico na sua formação, reflexo, entre outras coisas, da vivência curricular, logo no início do Ensino Fundamental, marcada pelo Imprinting Escolar Instrucionista. (VASCONCELLOS, 2011, p.33)

Conforme Gatti e Nunes (2009), estudos têm demonstrado que os cursos de formação superior de professores, as licenciaturas, apresentam modelos idealizados de alunos e professor, fazendo com que haja a predominância de estudos teóricos e das disciplinas de formação genérica em relação à formação para prática docente. Assim sendo, é preciso garantir que a formação inicial dos futuros professores aconteça por meio da articulação entre a teoria e as práticas educativas desenvolvidas no contexto escolar, permitido que a sala de aula seja um espaço para construção do saber docente.

Os estudos de Tardif (2002) ressaltam a necessidade de que a formação acadêmica do docente seja realizada por meio da articulação entre os saberes profissionais e os saberes experienciais; portanto, a sala de aula é o local mais expressivo para a formação docente, para que o aluno do curso de licenciatura possa aprender a ensinar e a torna-se professor.

A Lei de Diretrizes e Bases da Educação Nacional, Lei nº 9394/96, dedica especial atenção à formação de professores da educação básica apresentando dois artigos referentes aos tipos e modalidades de cursos para a formação de professores.

Art. 62. A formação de docentes para atuar na educação básica far-se-á em nível superior, em curso de licenciatura, de graduação plena, em universidades e institutos superiores de educação, admitida, como formação mínima para o exercício do magistério na educação infantil e nas quatro primeiras séries do ensino fundamental, a oferecida em nível médio, na modalidade Normal.

Art. 63. Os Institutos Superiores de Educação manterão:

1. cursos formadores de profissionais para a educação básica, inclusive o Curso Normal Superior, destinado à formação de docentes para a educação infantil e para as primeiras séries do ensino fundamental;

2. programas de formação pedagógica para portadores de diplomas de educação superior que queiram se dedicar à educação básica;

3. programas de educação continuada para os profissionais de educação dos diversos níveis (BRASIL, 1996).

Conforme os propósitos da Lei, a formação do docente deverá englobar o acesso a conhecimentos que valorizem uma prática de ensino de qualidade aliados à competência e habilidade que possibilitem a condução do processo pedagógico no cotidiano escolar.

Importante entendermos que a identidade do professor é construída tanto pelos significados sociais da profissão como pelas práticas profissionais.

A esse respeito Pimenta esclarece que:

A identidade é construída a partir da significação social da profissão, da revisão consiste dos significados sociais da profissão, da revisão constante dos significados sociais da profissão, da revisão das tradições. Mas também da reafirmação das práticas consagradas culturalmente e que permanecem significativas. Práticas que resistem a inovações porque prenhes de saberes válidos às necessidades da realidade. Do confronto entre as teorias e as práticas da análise sistemática das práticas à luz das teorias existentes, da construção de novas teorias (PIMENTA, 1999, p.19).

De acordo com Pimenta (1999), frente à demanda crescente do sistema de ensino é preciso pensar cuidadosamente na reformulação da identidade do professor. 
Segundo Tardif (2002), a identidade do professor deve estar baseada em princípios éticos, investigativos, críticos e reflexivos. Para o autor "o desenvolvimento da capacidade crítico-reflexiva é essencial na formação docente promovendo a interação com o conhecimento, gerando novos saberes e possibilitando a reconstrução da identidade do professor" (TARDIF, 2002, p.14).

O professor reflexivo é considerado o profissional que exerce plenamente as capacidades de pensamento e reflexão frente à realidade social, sabe agir de forma autônoma e coletivamente buscando as mudanças necessárias à prática educacional.

Pimenta (1999) aponta a necessidade de valorização do professor na sociedade atual contrapondo a todo um movimento existente de desvalorização da profissão. Para a autora a importância da profissão está aliada à construção da cidadania e ao enfrentamento do fracasso e das desigualdades escolares.

A identidade profissional não é algo imutável, mas é um processo de construção do sujeito historicamente situado. A profissão de professor, assim como tantas outras, responde a determinadas exigências sociais e se transforma no quadro de transformação societária.

A escolha da profissão carrega de certa forma algum saber sobre o que é ser professor, tanto pelas informações da sociedade como pela vivência nos espaços escolares. As mudanças históricas da profissão, as experiências de outros profissionais, bem como as representações da profissão pelos meios de comunicação também contribuem para os saberes da experiência. Segundo Pimenta (1999), os saberes da experiência são aqueles aprendidos pelo professor enquanto aluno, com os professores que teve na vida escolar, bem como os saberes que são produzidos pelo exercício e reflexão da prática, juntamente com outros professores.

Ao indagar sobre os conhecimentos necessários à docência, Pimenta (1999) recorre às contribuições de Moran (1993), que debatendo a ideia de que o conhecimento não se reduz à informação apresenta três estágios para a construção do conhecimento. O primeiro estágio é o da informação; o segundo é o do conhecer (trabalhar com as informações classificando-as, analisando-as e contextualizando-as), e o terceiro estágio refere-se à inteligência, entendida como a arte de vincular o conhecimento de maneira útil e pertinente.

O trabalho docente tem como principal finalidade possibilitar o conhecimento de forma crítica e transformadora. Segundo Pimenta (1999), na sociedade tecnológica e globalizada, o trabalho do professor consiste em possibilitar que os alunos trabalhem os conhecimentos científicos e tecnológicos, desenvolvendo habilidades para operá-los, revê-los com sabedoria e de forma interdisciplinar, rompendo com a tradição de um currículo fragmentado.

No entanto, se entendemos que conhecer não se reduz a informar, que não basta expor os meios de informação para adquiri-las, mas que é preciso operar com as informações na direção de, a partir delas, chegar ao conhecimento, então parece que a escola (e os professores) tem um grande trabalho a realizar com as crianças e os jovens, que é proceder à mediação entre a sociedade da informação e os alunos, no sentido de possibilitar-lhes, pelo desenvolvimento da reflexão, adquirirem a sabedoria necessária à permanente construção do conhecimento (PIMENTA, 1999, p. 8).

Para Pimenta, muitos alunos quando arguidos sobre o conceito de Didática afirmam que a Didática é "saber ensinar". Esta ideia traz embutido o reconhecimento de que a docência requer saberes da experiência, saberes do conhecimento e saberes didáticos.

No contexto atual, em que novos desafios são postos à educação, compete à didática contemporânea "proceder uma leitura crítica da prática social de ensinar, partindo da realidade existente, fazendo um balanço das iniciativas de se fazer frente ao fracasso escolar”. (PIMENTA, 1999, p.9) 
O saber fazer deve contribuir no próprio fazer, o que demanda uma relação intrínseca entre a teoria e a prática, uma constante reflexão da prática e da pesquisa da prática.

Embora Pimenta apresente essa tipologia de saberes, a autora reafirma a necessidade de que não ocorra a fragmentação desses saberes no exercício profissional e que para isso é essencial, além da formação inicial, a formação continuada dos professores aliando o saber ao saber fazer.

Frente à discussão dos saberes necessários à prática docente pode-se afirmar que a docência é uma atividade complexa e que requer uma formação ampla e adequada, capaz de contribuir para a formação de profissionais reflexivos e autônomos, conforme destaca Pimenta:

[...] professor não é uma atividade burocrática para a qual se adquire conhecimentos e habilidades técnico-mecânicas. Dada a natureza do trabalho docente, que é ensinar como contribuição ao processo de humanização dos alunos historicamente situados, espera-se da licenciatura que desenvolve nos alunos conhecimento e habilidades atitudes construindo seus saberes-fazeres docentes a partir das necessidades e desafios que o ensino como prática social lhes coloca no cotidiano. Espera-se, pois, que mobilize os conhecimentos da teoria da educação e da didática necessários à compreensão do ensino como realidade social, e que desenvolver neles a capacidade de investigar a própria atividade para, a partir dela, constituírem e transformarem os seus saberes-fazeres docentes, num processo contínuo de construção de suas identidades como professores (PIMENTA, 1999, p.18).

Considerando a importância da articulação entre a teoria e a prática na formação inicial do professor destacamos a relevância do Programa Institucional de Bolsas de Iniciação à docência - PIBID, resultado de uma ação do Governo Federal, gerenciado pela Coordenação de Aperfeiçoamento de Pessoal de Nível Superior - CAPES, destinada à formação de professores e à melhoria da educação básica brasileira.

\section{A EXPERIÊNCIA DO PIBID NA FORMAÇÃO DOS LICENCIANDOS DE PEDAGOGIA}

A Faculdade de Filosofia, Ciências e Letras de Ituverava - FFCL - é uma instituição filantrópica de ensino superior mantida pela Fundação Educacional de Ituverava que presta serviços educacionais há mais de 40 anos. Atualmente oferece cursos de graduação em diversas áreas do conhecimento e o curso de Pedagogia é a licenciatura que atende maior número de estudantes, tanto na modalidade presencial quanto a distância. O curso de Pedagogia é responsável pela formação inicial de uma parcela considerável de profissionais que atua na educação básica em Ituverava e em cidades da região.

Atentos à ampliação de oportunidades de formação e desenvolvimento de seus alunos, os coordenadores da Faculdade de Filosofia, Ciências e Letras de Ituverava tem participado e desenvolvido vários projetos e programas a partir das iniciativas do Governo Federal e Estadual. Um dos programas desenvolvidos é o Programa Institucional de Bolsas de Iniciação à Docência - PIBID - que teve seu início em 2012, de acordo com o edital CAPES № 11/2012 com ações em diversas licenciaturas. Em 2014 a instituição foi contemplada pelo edital CAPES N 61/2013 e desde então vem desenvolvendo ações nos cursos de licenciatura em Pedagogia, Letras, História e Biologia.

O projeto institucional, desenvolvido em subprojetos, tem como objetivo oportunizar aos graduandos dos cursos de licenciaturas vivenciar experiências formativas da prática pedagógica nas quais a aproximação com a realidade escolar permita a reflexão da prática e a construção de saberes teóricos, pedagógicos e experiências fundamentais necessárias ao exercício da docência. Além do fortalecimento da formação inicial dos graduandos, esse projeto visa, ainda, contribuir com a formação continuada dos 
professores da educação básica, por meio de um processo permanente de reflexão e ação da prática pedagógica.

Atualmente são desenvolvidos cinco subprojetos, sendo que um abrange os cursos de História e Pedagogia, chamado projeto Interdisciplinar. Participam do programa 44 licenciandos dos cursos citados, denominados de bolsistas de iniciação à docência, sendo que 22 são bolsistas do subprojeto de Pedagogia. Além dos licenciandos, o programa conta com a participação de 08 professores da educação básica, chamados professores supervisores. Também participam professores da Instituição de Ensino Superior IES - os quais exercem a função de coordenadores de área no projeto, que dentre suas atribuições desenvolvem e acompanham todas as atividades pertinentes ao subprojeto de atuação.

O Subprojeto de Pedagogia foi planejado e estruturado a partir da proposta de inserção de jogos como recurso pedagógico nas escolas de Ensino Fundamental. Esse tema foi selecionado após pesquisa realizada pelas docentes do curso de Pedagogia sobre as dificuldades enfrentadas pelos professores quanto ao processo de aprendizagem dos alunos, sobretudo no terceiro, quarto e quinto ano do ensino fundamental das escolas da cidade.

Com a pesquisa foi verificado que, de forma geral, as escolas municipais estavam com resultados preocupantes em relação aos processos de alfabetização e aquisição dos conhecimentos matemáticos averiguados em avaliações internas e externas; porém, na época estavam sendo desenvolvidas ações com enfoque no processo de alfabetização dos alunos como Pacto Nacional de Alfabetização, Programa Ler e Escrever, entre outras organizadas pelas escolas. Desta forma, percebeu-se que as iniciativas para o desenvolvimento do raciocínio lógico e das funções executivas eram raras, constituindo uma área potencial para intervenção e colaboração. Sendo assim, foi elaborado o subprojeto com o foco nos jogos na educação.

Atualmente há consenso entre estudiosos e profissionais da educação de que os jogos muito contribuem com o processo de ensino e aprendizagem, tanto nos aspectos emocionais e sociais quanto nos cognitivos, como defende Piaget (1978) e que potencializam o desenvolvimento das funções mentais superiores discutidas por Vygotsky (1987), e valorizadas pelas neurociências, pois:

[...] podem favorecer observações e possibilitar análises, promovendo processos favoráveis ao desenvolvimento e a aprendizagem de competências e habilidades dos alunos para pensar e agir com razão diante dos conteúdos que enfrentam em sua educação básica. (MACEDO, 2009, p. 8)

Por meio dos jogos os alunos são motivados a prestar atenção e a concentrar-se, superar dificuldades, elaborar estratégias, avaliar possibilidades e tomar decisões, antecipar, memorizar e recuperar conteúdos e informações, respeitar e negociar limites e regras, considerar o ponto de vista do outro, superar o egocentrismo, interagir com os pares, considerar a reciprocidade, ler, escrever, interpretar e compreender instruções, raciocinar, calcular, lidar com perdas e ganhos, desenvolver autonomia e ser protagonista na construção do seu próprio conhecimento.

Historicamente, estudiosos têm enfatizado a relevância do jogo não só na vida das crianças, mas também na dos adultos. Macedo; Petty; Passos (2005) chamam a atenção para a utilização dessa estratégia de aprendizagem não apenas como diversão, mas como um excelente meio para a construção do conhecimento em situações formais de aprendizagem. Segundo os Parâmetros Curriculares Nacionais - PCNs - (MEC, 1997), o jogo para as crianças é muito prazeroso, instigante e genuíno, pois gera interesse e prazer. Por isso, é relevante a iniciativa de inclui-los na educação e no convívio escolar.

$\mathrm{Na}$ sala de aula geralmente o aluno é passivo e depende quase sempre do professor. Para que ocorra a aprendizagem é interessante que as atividades sejam envolventes e que o educando possa se 
utilizar de desafios e descobertas. Consideram-se prementes novas metodologias de ensino em que os alunos demonstrem menos dependência e que sejam sujeitos da aprendizagem. Nesse sentido, a introdução dos jogos como estratégia de ensino e de aprendizagem pode resultar em sucesso, pois, dentre outras competências, estimula a criatividade em situações desafiadoras, a investigação e a resolução de situações problema.

Para Piaget (1978), o jogo é essencial na vida da criança e possibilita o desenvolvimento de estruturas para o conhecer e o viver. Sempre que se joga, se desperta o desejo da repetição e do aperfeiçoamento que causam prazer funcional. Segundo Macedo (2010, s.p.):

É importante compreender que vida e conhecimento não são jogos, mas que as formas de viver e conhecer, são. É por meio deles que exercitamos, simbolizamos e aperfeiçoamos nossas maneiras de interagir com as pessoas e as coisas e de proceder bem. Quando o tornar-se lúcido é mediado pelo lúdico, o amor ao conhecimento e às pessoas encontra realização e sentido.

Para Vygotsky (1989), o sujeito é interativo e por isso dá muita importância à fala. Em sua interpretação, a fala e a ação fazem parte da mesma função psicológica complexa. Nesse sentido, quanto mais complexa a ação, maior necessidade de habilidades de linguagem. Essa capacidade contribui com a criança no sentido de se relacionar, de se controlar e na resolução de problemas. $\mathrm{O}$ autor também estabelece uma estreita relação entre as brincadeiras, o jogo e a aprendizagem, afirmando que o desenvolvimento cognitivo resulta da interação entre a criança e as pessoas com as quais convive.

Considerando o importante papel dos jogos como recurso para o desenvolvimento das habilidades e competências dos alunos e a contribuição para o êxito no processo de aprendizagem de todos os componentes curriculares, as ações planejadas para o subprojeto PIBID de Pedagogia visam contribuir com a inserção de jogos, em algumas escolas municipais de Ensino Fundamental de Ituverava- SP.

O subprojeto tem como objetivos ampliar os conhecimentos dos docentes das escolas de educação básica sobre o papel dos jogos na educação instigando-os a também utilizar os jogos como recursos didáticos, e colaborar com o desenvolvimento discente nas habilidades de atenção, concentração, percepção, planejamento, memória, linguagem, entre outros que são requisitos básicos parao processo de aprendizagem dos alunos na alfabetização, leitura, escrita, cálculo e resolução de problemas.

Esses objetivos se agregam aos objetivos do Projeto institucional que pretende:

\footnotetext{
- incentivar a formação de docentes em nível superior para a educação básica;

- contribuir para a valorização do magistério;

- inserir os licenciandos no cotidiano de escolas da rede pública de educação, proporcionando-lhes oportunidades de criação e participação em experiências metodológicas, tecnológicas e práticas docentes de caráter inovador e interdisciplinar que busquem a superação de problemas identificados no processo de ensinoaprendizagem;

- elevar a qualidade da formação inicial de professores nos cursos de licenciatura, promovendo a integração entre educação superior e educação básica;

- incentivar escolas públicas de educação básica, mobilizando seus professores como coformadores dos futuros docentes e tornando-as protagonistas nos processosde formação inicial para o magistério; e

- contribuir para a articulação entre teoria e prática necessárias à formação dos docentes, elevando a qualidade das ações acadêmicas nos cursos de licenciatura (CAPES, 2013)
}

Com vistas a alcançar os objetivos estabelecidos foram propostas 13 ações, que ao longo do período de aplicação do subprojeto, têm se mostrado de grande relevância. 


\section{1 - Formação do aluno bolsista e do professor supervisor}

Periodicamente são realizadas reuniões com professores coordenadores de área, professor supervisor e alunos bolsistas, para estudo e reflexão sobre temas relativos ao subprojeto, com a finalidade de promover melhoria na formação inicial de professores e contribuir com a formação continuada dos docentes que atuam na educação básica, bem como oferecer subsídio teórico e prático para a implementação do subprojeto nas escolas de ensino fundamental contribuindo para a valorização do magistério e elevação da qualidade das ações acadêmicas no curso de licenciatura. Essas reuniões têm se constituído como importantes momentos formativos e de troca de experiências.

\section{2 - Realização de pesquisa sobre os jogos no contexto educacional}

Sob orientação dos professores coordenadores do subprojeto, os alunos bolsistas realizam pesquisas sobre o papel dos jogos no processo de ensino e aprendizagem, a metodologia oportuna para o desenvolvimento de competências, habilidades e estímulo ao desenvolvimento das funções mentais superiores; os tipos de jogos adequados para a faixa etária em questão e como utilizá-los no contexto escolar, visando apropriação e aprofundamento teórico para a realização do planejamento e execução das propostas. Essa ação contribui para o desenvolvimento de competências e habilidades relacionadas à prática da pesquisa que envolve a seleção dos materiais, o estudo, a reflexão e a sistematização de informações para que estas posteriormente sejam compartilhadas com o grupo de licenciandas e de supervisoras.

\section{3 - Apresentação do projeto aos gestores e grupo de educadores na escola de ensino fundamental}

As ações do subprojeto são apresentadas à gestão e aos professores da escola por meio de reuniões, exposição de trabalhos e participação em salas de aula, com o intuito de construir a identidade do subprojeto de Pedagogia juntamente com docentes e equipe gestora das escolas de educação básica. Essa ação possibilita que todos que atuam no contexto escolar possam refletir sobre os objetivos do projeto, conhecer suas principais ações, coletar informações para o planejamento das propostas e incorporar sugestões do grupo de educadores da escola, valorizando o trabalho coletivo e garantindo maior envolvimento e possibilidades de continuidade do trabalho.

\section{4 - Formação do grupo de educadores na escola de ensino fundamental}

A contribuição do PIBID com a formação continuada dos docentes da escola de ensino fundamental ocorre por meio da participação desses professores nas reuniões com as coordenadoras do subprojeto, apresentando e disponibilizando materiais para desenvolvimento dos jogos, e na participação nos eventos do PIBID. Nesses encontros são valorizadas a utilização de metodologias envolvendo jogos e a importância da sua inserção no cotidiano escolar, abrangendo os aspectos teóricos e práticos, com o intuito de promover maior integração entre a educação superior e a básica, elevar o nível de formação dos docentes que atuam nas escolas que sediam o subprojeto possibilitando-lhes a introdução de novas estratégias didáticas e diferentes recursos pedagógicos.

\section{5 - Participação das licenciandas nas reuniões pedagógicas da unidade escolar}

A participação das licenciandas nas reuniões pedagógicas da escola possibilita a vivência nas diversas situações do cotidiano escolar, permitindo-lhes conhecer situações de formação e reflexão sobre a teoria e a prática, analisar casos didáticos e pedagógicos e participar do planejamento, implementação e avaliação do Projeto Político Pedagógico. Assim, essa participação possibilita que os professores da 
educação básica contribuam com a formação inicial das bolsistas, atuando como coformadores de futuros docentes.

\section{6 - Definição dos jogos}

A realização das pesquisas sobre a utilização dos jogos e a troca de experiências com professores supervisores fornecem subsídios necessários para que as licenciandas selecionem os jogos que serão utilizados, tendo como referência o desenvolvimento de competências e habilidades dos alunos, tais como: manter a atenção, concentrar-se, elaborar estratégias, antecipar, memorizar, ler, escrever, compreender instruções, raciocinar, calcular, lidar com perdas e ganhos, entre outros. Os jogos são selecionados de acordo com o nível de desenvolvimentos dos alunos, seus interesses e suas necessidades, sendo que o mesmo jogo é aplicado para todas as classes do mesmo ano, por um período determinado. Desta forma, o processo decisório também depende da participação coletiva de todas as licenciandas. Ao longo do período de vigência do subprojeto foram utilizados diversos jogos, sendo que muitos foram confeccionados pelas licenciandas. Dentre os jogos utilizados destacam-se: Tangran, Jogo da velha, Dama, Trilha (percurso), Dominó, Jogo da memória, Resta 1, Super Trunfo, Uno, Baralho, Bingo, Lince, Sodoku, Quatro em linha, Imagem e ação, Perfil Júnior, Cara-a-cara, entre outros. Algumas escolhas atenderam às necessidades e as características do desenvolvimento dos alunos possibilitando a realização de ações muito interessantes, outros, porém, tiveram que ser substituídos ora por não despertar o interesse dos alunos, ora por exigir habilidades além ou aquém das apresentadas por eles.

\section{7 - Planejamento das ações e elaboração de materiais didáticos}

O planejamento das ações tem como base a análise do processo de ensino e aprendizagem, as diretrizes e currículos educacionais da educação básica, a rotina e característica das classes e o diagnóstico dos alunos. O planejamento objetiva relacionar a teoria com a prática e possibilitar que ao longo da implementação do projeto as licenciandas adquiram maior autonomia para planejar, desenvolver e avaliar as ações, sendo essas propostas em níveis crescentes de complexidade. Inicialmente o processo de planejamento é direcionado pelas coordenadoras do subprojeto e, de acordo com o desenvolvimento das licenciandas, estas passam a realizar o planejamento de forma autônoma. Para cada jogo são planejadas de quatro a seis oficinas que envolvem, além das atividades que expõem as origens do jogo, as regras e os procedimentos, operações matemáticas, produções de textos, confecção dos jogos, entre outras atividades. As ações planejadas são avaliadas pelas professoras coordenadoras e pelas supervisoras, que também são responsáveis por contribuir com o planejamento da aplicação.

\section{8 - Implementação das ações com os alunos do ensino fundamental (aplicação das oficinas de jogos)}

Semanalmente as alunas bolsistas desenvolvem as atividades planejadas (oficina de jogos) com os alunos das salas em que o projeto é desenvolvido, com o acompanhamento do professor responsável pela sala. Essa ação oportuniza às licenciandas a criação e participação em experiências metodológicas e práticas docentes de caráter inovador buscando contribuir com a superação de problemas identificados no processo de ensino e aprendizagem. Inicialmente muitas licenciandas encontraram dificuldades para manter a disciplina da turma e realizar as atividades dentro do tempo disponível, porém, ao longo do período muitas já se apropriaram do contexto escolar e conseguiram se adaptar às especificidades da sala de aula. Outra ação de destaque das licenciandas do PIBD é que parte da aula é dedicada ao acompanhamento de alunos com dificuldades de aprendizagem. 


\section{9 - Elaboração de relatórios das ações}

Uma das ações de destaque no PIBID é o desenvolvimento da competência escritora, pois todas as ações desenvolvidas são devidamente registradas, ou seja, após cada ação a aluna bolsista elabora relatório apresentando: nome da ação, aspectos relevantes da aplicação da atividade ou estudo do texto, participação dos alunos e resultados obtidos. Essa ação possibilita melhor acompanhamento da atuação das licenciandas além de oportunizar a ampliação e o aperfeiçoamento do uso da língua portuguesa em situações formais.

\section{0 - Construção de um portfólio para o registro das ações desenvolvidas}

Cada licencianda constrói um portfólio (individual) para apresentação de todas as ações realizadas. Nesse documento estão reunidos todos os registros das atividades, como pautas e relatórios de reuniões, estudos diversos, planos de ação e registros das oficinas desenvolvidas com os alunos. Nesses registros são descritas as competências e habilidades priorizadas, informações sobre o desenvolvimento da proposta, e sempre que possível são inseridas fotos, cópia de atividades dos alunos e demais formas de registro que a licencianda julgar pertinente. Essa ação contribui com a sistematização das atividades, possibilita melhor visualização das ações e a divulgação dos resultados alcançados. A elaboração do portfólio também é acompanhada pelas professoras coordenadoras.

\section{1 - Avaliação do projeto pela escola participante}

São feitas reuniões com a equipe escolar para avaliação do projeto, bem como para adequação ou necessidade de reformulação das ações desenvolvidas. Com isso almeja-se o estabelecimento do diálogo e a articulação dos membros do programa e da comunidade escolar e o desenvolvimento de um trabalho que contribua para a redução dos problemas enfrentados pelas escolas da rede municipal quanto ao baixo rendimento dos alunos na alfabetização e nos conhecimentos matemáticos.

\section{2 - Socialização e discussão do projeto e dos resultados com os colegas}

As ações desenvolvidas no subprojeto de Pedagogia são socializadas de forma não sistematizada, por meio da troca de informações entre as licenciandas e de forma sistemática por meio da apresentação dos resultados do trabalho desenvolvido em eventos do PIBID e eventos científicos dentro e fora da faculdade. O trabalho também é divulgado por meio de publicações em revistas científicas e na página da faculdade, no espaço reservado para o projeto PIBID.

\section{3 - Apresentação de trabalhos em eventos científicos}

As licenciandas e supervisoras são estimuladas a participar de eventos científicos e a apresentar trabalhos desenvolvidos no subprojeto de Pedagogia. A publicação em periódicos científicos, discutindo os resultados das reflexões realizadas, socializando as ações desenvolvidas, os impactos e os resultados alcançados são de grande relevância para o Projeto, para as licenciandas e para os demais alunos, oportunizando a ampliação e o aperfeiçoamento do uso da Língua Portuguesa, a divulgação de práticas inovadoras e a sistematização dos saberes e peculiaridades do fazer docente.

De acordo com relatos das licenciandas e das supervisoras, as ações desenvolvidas pelo subprojeto PIBID de Pedagogia estão atingindo seus objetivos e produzindo resultados importantes na vida escolar dos alunos. 


\section{CONSIDERAÇÕES FINAIS}

O subprojeto de Pedagogia, do PIBID da FFCL de Ituverava, desenvolvido nas séries inicias do ensino fundamental das escolas públicas municipais de Ituverava enfoca o trabalho com jogos no contexto educacional e tem alcançado resultados significativos, tanto no que se refere à formação das licenciandas que são unânimes em ressaltar os benefícios que a participação no projeto oportuniza, quanto para o processo de construção de conhecimentos dos alunos da educação básica que vivenciam situações ricas e diversificadas de aprendizagem, e ainda, para o aprimoramento das práticas pedagógicas desenvolvidas pelas professoras e supervisoras que atuam no PIBID.

Os resultados parciais do subprojeto demonstram a introdução de novas estratégias didáticas e metodológicas, colaborando para a motivação e para a superação de dificuldades do processo de ensino e aprendizagem. A vivência de experiências formativas da prática pedagógica e a aproximação com a realidade escolar favoreceram às licenciandas o desenvolvimento da autonomia e do protagonismo na construção do conhecimento. Além da construção de novos conhecimentos teóricos, as licenciandas tiveram a oportunidade de se inserir no cotidiano das escolas e vivenciar atividades importantes para a construção da identidade docente. Pode-se também ressaltar a relevância da interação entre a IES e as escolas de educação básica, contribuindo para a troca de saberes entre a universidade e as escolas públicas, a implementação de novas metodologias de ensino e a formação continuada dos professores.

Os resultados positivos obtidos com a realização do subprojeto de Pedagogia evidenciam a relevância do PIBID enquanto política pública destinada à melhoria na formação de professores e na qualidade da educação básica.

\section{REFERÊNCIAS}

BRASIL. Conselho Nacional de Educação. Resolução CNE/CP n. 1, de 15 de maio de 2006. Brasília, DF, Diário Oficial da União, n.92, seção 1, p.11- 12, 16 maio 2006.

Lei n. 9.394, de 20 de dezembro de 1996. Estabelece as diretrizes e bases da educação nacional. Diário Oficial [da] República Federativa do Brasil, Brasília, DF, 23 dez. 1996. p. 27-33. Disponível em: <http://www.planalto.gov.br/ccvil_03/LEIS/19394.htm>. Acesso em: 10 jul. 2017.

CAPES. Coordenação de Aperfeiçoamento de Pessoal de Nível Superior. Portaria n. 096 de 18 de julho de 2013. Disponível em:

<https://www.capes.gov.br/images/stories/download/legislacao/Portaria_096_18jul13_AprovaRegulament oPIBID.pdf.>. Acesso em: 10 jul. 2017.

GATTI, B. A.; NUNES, M. Formação de professores para o ensino fundamental: estudo de currículo das licenciaturas em pedagogia, língua portuguesa, matemática e ciências biológicas. São Paulo: Fundação Carlos Chagas, 2007.

MACEDO, L. Jogar para viver e conhecer. Revista Nova escola, 1 set. 2010. Disponível em: <https://novaescola.org.br/conteudo/590/jogar-para-viver-e-conhecer〉. Acesso em 15 jul. 2017.

Artmed, 2005.

; PETTY, A. L. S.; PASSOS, N. C. Os jogos e o lúdico na aprendizagem escolar. Porto Alegre:

(org). Jogos, psicologia e educação: teoria e pesquisas. São Paulo: Casa do Psicólogo, 2009.

PIAGET, J. A formação do símbolo na criança. Rio de Janeiro: Guanabara Koogan, 1978. 
PIMENTA, S.G. Formação de professores-saberes da docência e identidade do professor. Revista Nuances, vol. III, p.5-14. Disponível em:

<http://revista.fct.unesp.br/index.php/Nuances/article/viewArticle/50. >. Acesso em: 15 jul. de 2015.

Formação de professores: identidade e saberes da docência. In: . (Ed.). Saberes

pedagógicos e atividade docente. São Paulo: Cortez, 1999.

TARDIF, M. Saberes docentes e formação profissional. Rio de Janeiro: Vozes, 2002.

VASCONCELLOS, C. S. Formação didática do educador contemporâneo: desafios e perspectivas. In: UNIVERSIDADE ESTADUAL PAULISTA. Prograd. Caderno de Formação: formação de professores didática geral. São Paulo: Cultura Acadêmica, v. 9. 2011, p. 33-58.

VYGOTSKY, L. S. Pensamento e linguagem. São Paulo: Martins Fontes, 1987.

A formação social da mente: o desenvolvimento dos processos psicológicos superiores. 3.ed. São Paulo: Martins Fontes, 1989. 